\title{
Influence of Miscibility of Protein-Sugar Lyophilizates on Their Storage Stability
}

\author{
Maarten A. Mensink, ${ }^{1}$ Matthew J. Nethercott, ${ }^{2,3}$ Wouter L. J. Hinrichs, ${ }^{1,6}$ Kees van der Voort Maarschalk,,${ }^{1,4}$ \\ Henderik W. Frijlink, ${ }^{1}$ Eric J. Munson, ${ }^{2,6}$ and Michael J. Pikal ${ }^{5}$
}

Received 19 April 2016; accepted 24 May 2016; published online 14 June 2016

\begin{abstract}
\begin{tabular}{lll}
\hline ABSTRACT. & For sugars to act as successful stabilizers of proteins during lyophilization
\end{tabular} and subsequent storage, they need to have several characteristics. One of them is that they need to be able to form interactions with the protein and for that miscibility is essential. To evaluate the influence of protein-sugar miscibility on protein storage stability, model protein IgG was lyophilized in the presence of various sugars of different molecular weight. By comparing solid-state nuclear magnetic resonance spectroscopy relaxation times of both protein and sugar on two different timescales, i.e., ${ }^{1} \mathrm{H} \mathrm{T}_{1}$ and ${ }^{1} \mathrm{H} \mathrm{T}_{1 \rho}$, miscibility of the two components was established on a 2-5- and a 20-50-nm length scale, respectively, and related to protein storage stability. Smaller sugars showed better miscibility with $\mathrm{IgG}$, and the tendency of IgG to aggregate during storage was lower for smaller sugars. The largest sugar performed worst and was phase separated on both length scales. Additionally, shorter protein ${ }^{1} \mathrm{H} \mathrm{T}_{1}$ relaxation times correlated with higher aggregation rates during storage. The enzymelinked immunosorbent assay (ELISA) assay showed overlapping effects of aggregation and chemical degradation and did not correspond as well with the miscibility. Because of the small scale at which miscibility was determined $(2-5 \mathrm{~nm})$ and the size of the protein domains $(\sim 2.5 \times 2.5 \times 5 \mathrm{~nm})$, the miscibility data give an indirect measure of interaction between protein and sugar. This reduced interaction could be the result of steric hindrance, providing a possible explanation as to why smaller sugars show better miscibility and storage stability with the protein.
\end{abstract}

KEY WORDS: homogeneity; immunoglobulin G (IgG); phase separation; solid-state nuclear magnetic resonance spectroscopy (ssNMR); steric hindrance.

\section{INTRODUCTION}

Protein pharmaceuticals have become increasingly important in the pharmaceutical industry over the past decade, with 10 out of the 41 drugs approved by the American Food and Drug Administration (FDA) in 2014 being proteins (1).

Electronic supplementary material The online version of this article (doi:10.1208/s12248-016-9937-7) contains supplementary material, which is available to authorized users.

\footnotetext{
${ }^{1}$ Department of Pharmaceutical Technology and Biopharmacy, University of Groningen, Antonius Deusinglaan 1, 9713 AV, Groningen, The Netherlands.

${ }^{2}$ Department of Pharmaceutical Sciences, University of Kentucky, 789 South Limestone Street, Lexington, Kentucky 40536-0596, USA.

${ }^{3}$ Present Address: Kansas Analytical Services, Fort Collins, Colorado, USA.

${ }^{4}$ Process Technology, Corbion Purac, Gorinchem, The Netherlands.

${ }^{5}$ Department of Pharmaceutical Sciences, University of Connecticut, Storrs, Connecticut, USA.

${ }^{6}$ To whom correspondence should be addressed. (e-mail: W.L.J.Hinrichs@rug.nl; eric.munson@uky.edu; )
}

Most protein formulations are produced as solutions requiring refrigerated storage and handling, the so-called cold chain. This is both costly and impractical. The cold chain can be circumvented by drying the protein formulation in the presence of a stabilizer, using methods such as lyophilization and spray drying $(2,3)$. For these situations, sugars are often used as stabilizers.

Much research has been done into the mechanism by which these sugars stabilize proteins both during drying and storage (4-6), producing several widely discussed theories regarding these mechanisms (e.g., vitrification theory, the water replacement theory, and refinements focusing on local mobility of the protein) $(5,7)$. For each of those theories, interactions between protein and sugar are needed, and for that, miscibility of the protein and sugar is a necessary condition.

To qualify solids as miscible or immiscible, it is important to define the scale of this miscibility and the technique used to quantify miscibility. Two substances can appear miscible using a technique that measures a larger domain size, while showing phase separation using a technique that measures a smaller domain size. Therefore, a definition of miscibility should be accompanied by a qualification of the scale at 
which it was established. In this manuscript, miscibility was determined using solid-state nuclear magnetic resonance spectroscopy (ssNMR). The method uses the concept of spin diffusion to determine the homogeneity of mixed systems (8). In homogeneous systems, spin diffusion causes magnetization transfer between neighboring nuclei, resulting in similar relaxation times for both nuclei. For phase separated systems, magnetization transfer does not occur and the relaxation times of different components are not averaged.

Spin diffusion is a time-dependent phenomenon and the length scale of spin diffusion $L$ is correlated to the relaxation time as follows:

$L=\sqrt{6 D t}$

$D$ is the spin diffusion coefficient, which is typically assumed to be $10^{-12} \mathrm{~cm}^{2} / \mathrm{s}(9,10)$ and $t$ is the relaxation time. When relaxation times of different timescales are compared, this principle allows differentiation of homogeneity on different length scales. In particular, a spin-lattice relaxation time $\left({ }^{1} \mathrm{H} \mathrm{T}_{1}\right)$ is typically $1-5 \mathrm{~s}$, corresponding to a spin diffusion over a distance of approximately $20-50 \mathrm{~nm}$, while a rotating frame spin-lattice relaxation time $\left({ }^{1} \mathrm{H} \mathrm{T}_{1 \rho}\right)$ is usually $5-50 \mathrm{~ms}$ during which spin diffusion occurs over a distance of around 2-5 $\mathrm{nm}$.

By comparing ${ }^{1} \mathrm{H} \mathrm{T}_{1}$ and ${ }^{1} \mathrm{H} \mathrm{T}_{1 \rho}$ relaxation times of different components in a mixture, in this case protein and sugar, it is thus possible to establish the intimacy of mixing on two different length scales (Fig. 1). If a system is fully miscible, both the relaxation times will be similar for both components. If a system is phase separated, both ${ }^{1} \mathrm{H} \mathrm{T}_{1}$ and ${ }^{1} \mathrm{H} \mathrm{T}_{1 \rho}$ values will be different for the sugar and protein. When the ${ }^{1} \mathrm{H} \mathrm{T}_{1 \rho}$ values are different, but the ${ }^{1} \mathrm{H} \mathrm{T}_{1}$ values are similar, this indicates phase separation on the $2-5-\mathrm{nm}$ scale but miscibility on the $20-50-\mathrm{nm}$ scale (partial phase separation). Using these relaxation times, it is thus possible to determine miscibility of these systems on two different length scales.

Recently, it was shown that larger and molecularly more rigid sugars (e.g., oligo- and polysaccharides with a backbone through the sugar ring) are less efficient stabilizers of proteins than smaller sugars (e.g., disaccharides) (11). It was found that these larger sugars form fewer hydrogen bonds with the protein during the last part of lyophilization (12). This lack of interactions could be responsible for phase separation in these protein-sugar mixtures. Therefore, the influence of protein-sugar miscibility on protein stability will be investigated in this manuscript.

\section{MATERIALS AND METHODS}

\section{Materials}

Immunoglobulin $\mathrm{G}$ ( $\mathrm{IgG}$, from bovine serum) was obtained from Sigma-Aldrich, St. Louis, MO, USA. Trehalose was acquired from Ferro Pfanstiehl (Waukegan, IL, USA) and dextrans 1.5, 5, and $70 \mathrm{kDa}$ from Pharmacosmos (Holbaek, Denmark). Inulins 1.8 and $4 \mathrm{kDa}$ were generous gifts from Sensus (Roosendaal, The Netherlands). Sodium phosphate buffer components used for the formulations and dialysis (monobasic as monohydrate, dibasic as heptahydrate) were purchased at Fisher Scientific.

\section{Formulation Preparation}

IgG was received frozen and thawed slowly on ice prior to use. The protein solution ( $\mathrm{IgG}$ ) was dialyzed at least three times for a minimum of $3 \mathrm{~h}$ against $2 \mathrm{mM}$ sodium phosphate buffer ( $\mathrm{pH} 7.5, \mathrm{SPB})$ at $4^{\circ} \mathrm{C}$ using a Spectra/Por ${ }^{\circledR} 6$ dialysis tube membrane with a molecular weight cutoff of 2000 Da. After dialysis, the protein solution was filtered using MillexGV low-protein binding PVDF syringe filters with a $0.22-\mu \mathrm{m}$ pore size and 33-mm diameter. Subsequently, protein concentration was determined spectroscopically at $280 \mathrm{~nm}$, using absorption coefficients $A_{1} \mathrm{~cm} \%=14$ (13). The protein stock solution concentration was adjusted to $10.71 \mathrm{mg} / \mathrm{mL}$ by dilution with filtered SPB. Sugar stock solutions were prepared by dissolving sugars in SPB to a concentration of $100 \mathrm{mg} / \mathrm{mL}$. If needed, solutions were heated to dissolve the sugar. All formulations were also filtered using $0.22 \mu \mathrm{M}$ PVDF filters. Protein and sugar solutions were mixed to achieve an end concentration of $6 \mathrm{mg} / \mathrm{mL}$ protein and $44 \mathrm{mg} /$ $\mathrm{mL}$ sugar (12\% protein on dry solids basis). When IgG and dextran $70 \mathrm{kDa}$ were mixed, some hazing was observed in the resulting solution. The solutions were transferred to Schott Fiolax ${ }^{\circledR}$ tubular vials of $10 \mathrm{~mL}$ with a $13-\mathrm{mm}$ opening. For samples for physicochemical testing, a fill volume of $5 \mathrm{~mL}$ was used, and for stability testing, a fill volume of $1 \mathrm{~mL}$ was used.

\section{Lyophilization}

Freeze-drying was conducted using a SP Scientific LyoStar 3 (Warminster, PA, USA) equipped with Praxair ControLyo ${ }^{\mathrm{TM}}$ controlled ice nucleation technology. Compared to slow freezing, controlled nucleation is expected to reduce the risk of phase separation during freezing by saturation of either of the components and increase sample homogeneity. Controlled nucleation is thus expected not to have a negative impact on miscibility. Samples were placed on a shelf precooled at $5^{\circ} \mathrm{C}$ and kept at that temperature for $30 \mathrm{~min}$. The temperature was then lowered to $-5^{\circ} \mathrm{C}$ at a rate of $1^{\circ} \mathrm{C} / \mathrm{min}$ and held at that temperature for $30 \mathrm{~min}$. Controlled nucleation was then induced using argon as a carrier gas, followed by further cooling to $-40^{\circ} \mathrm{C}$ at a rate of $1^{\circ} \mathrm{C} / \mathrm{min}$. After $60 \mathrm{~min}$ at that temperature, the pressure was lowered to $87 \mu \mathrm{bar}$ and the temperature was raised to $-25^{\circ} \mathrm{C}$ at $1^{\circ} \mathrm{C} / \mathrm{min}$. Sample temperature of at least five vials was monitored using thermocouples. Shelf temperature was lowered to $-28^{\circ} \mathrm{C}$ if primary drying was not done after $30 \mathrm{~h}$ or if the product temperature would exceed $-33^{\circ} \mathrm{C}$. The end of primary drying was established by comparative pressure measurement (i.e., Pirani vs. MKS Baratron) (14). After primary drying was completed, the shelf temperature was slowly raised to $40^{\circ} \mathrm{C}$ at a rate of $0.1^{\circ} \mathrm{C} / \mathrm{min}$ and secondary drying was continued for $6 \mathrm{~h}$ at this temperature. Lastly, the vials were stoppered in the freeze dryer at $87 \mu$ bar using Flurotec ${ }^{\mathrm{TM}}$ stoppers and were sealed with aluminum crimpers upon removal from the freeze dryer. All samples were stored at $-20^{\circ} \mathrm{C}$ up until the moment of analysis. Water content of the lyophilizates was determined using Karl Fisher coulometry and was found to be $\leq 0.25 \%$ for all tested formulations. 


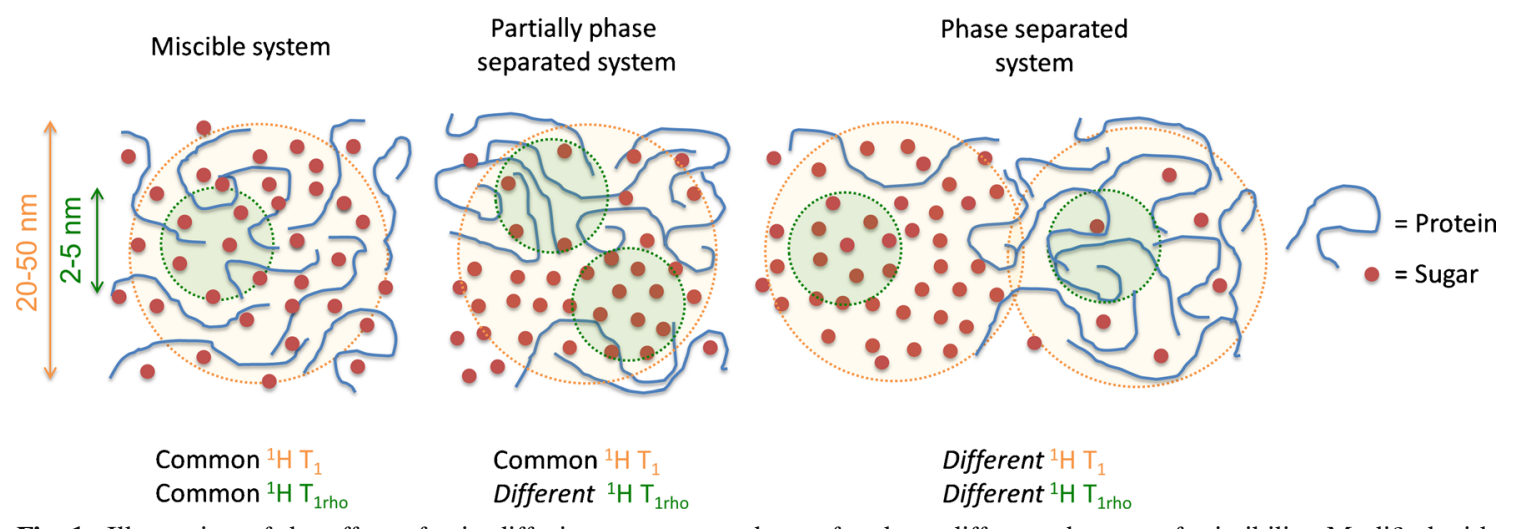

Fig. 1. Illustration of the effect of spin diffusion on measured area for three different degrees of miscibility. Modified with permission from Yuan et al. (8). Copyright 2015 American Chemical Society

\section{Solid-State Nuclear Magnetic Resonance Spectroscopy}

All solid-state NMR spectra were acquired using a Tecmag Redstone HF3 (Tecmag, Houston, TX) spectrometer operating at $100.6 \mathrm{MHz}$ for ${ }^{13} \mathrm{C}$ (9.4 T static magnetic field). The lyophilized powders were packed into $7-\mathrm{mm}$ zirconia rotors and sealed with Kel-F end-caps (Revolution NMR, LLC, Fort Collins, CO) in a glovebox purged with dry nitrogen gas with a relative humidity of $<1 \%$. Experiments were performed using a 7 -mm double resonance magic angle spinning (MAS) probe (Agilent, Palo Alto, CA). All ${ }^{13} \mathrm{C}$ spectra were acquired under MAS (15) at $4 \mathrm{kHz}$, using ramped-amplitude cross-polarization (CP) (16), total sideband suppression (TOSS) (17), and spinal64 decoupling (18) with a ${ }^{1} \mathrm{H}$ decoupling field of about $66 \mathrm{kHz}$. A 2-ms contact time was used in all experiments. 3-Methylglutaric acid was used to optimize spectrometer settings, and the methyl peak was referenced to $18.84 \mathrm{ppm}$ (19). All spectra were acquired at ambient temperature.

\section{Determination of Phase Separation}

To evaluate phase separation of the protein and sugar, the ${ }^{1} \mathrm{H} \mathrm{T}_{1}$ and ${ }^{1} \mathrm{H} \mathrm{T}_{1}$ values were determined. The ${ }^{1} \mathrm{H} \mathrm{T}_{1}$ relaxation values were measured using a saturation recovery experiment through ${ }^{13} \mathrm{C}$ observation. The peak areas were integrated and plotted in KaleidaGraph (Synergy Software, Reading, PA) and fitted to the following equation to determine ${ }^{1} \mathrm{H} \mathrm{T}_{1}$ times for the protein and the sugar peaks individually:

$M=M_{0}\left(1-e\left(-t / T_{1}\right)\right)$

where $M$ is the integrated signal intensity, $M_{0}$ is an amplitude parameter from the fit, $\tau$ is the recovery delay time, and ${ }^{1} \mathrm{H} T_{1}$ is the obtained spin-lattice relaxation time. The protein peak was integrated in the $\sim 164-180$-ppm region, whereas for the sugar peak, the $\sim 90-106-p p m$ region was used. Only the central one third of the peaks was used. These peaks were chosen because of the lack of overlap between the two species in those areas. For the ${ }^{1} \mathrm{H} \mathrm{T}_{1 \rho}$ experiment, the spin locking time was varied from 1 to $30 \mathrm{~ms}$. Similar to the
${ }^{1} \mathrm{H} \mathrm{T}_{1}$ experiments, Kaleidograph was used for integration and fitting of the data using formula 3.

$M=M_{0} e\left(-t / T_{1 \mathrm{p}}\right)$

The symbols are the same as used in formula $2 .{ }^{1} \mathrm{H} \mathrm{T}_{1 \mathrm{p}}$ is the rotating frame spin-lattice relaxation time.

Data acquisition parameters for the ${ }^{1} \mathrm{H} \mathrm{T}_{1}$ experiments were a 1-s recycle delay, 2048 acquisition points $(51.2 \mathrm{~ms}$ acquisition time), a $3.8-\mu \mathrm{s}{ }^{1} \mathrm{H} 90^{\circ}$ pulse ( $\sim 66 \mathrm{kHz}$ decoupling field), a 2-ms contact time, and a 4-kHz MAS frequency. Twelve time points $(0.1,0.3,1.2,1.8,3.0,4.0,9.0$, and $15 \mathrm{~s})$ were used in the ${ }^{1} \mathrm{H} \mathrm{T}_{1}$ determination, and 500 acquisitions were acquired per $T_{1}$ point. Data acquisition parameters for the ${ }^{1} \mathrm{H} \mathrm{T}_{1 \text { rho }}$ experiments were a 4-s recycle delay, 2048 acquisition points (51.2 ms acquisition time), a $3.8-\mu \mathrm{s}{ }^{1} \mathrm{H} 90^{\circ}$ pulse ( $\sim 66 \mathrm{kHz}$ decoupling field), a 2-ms contact time, and a 4-kHz MAS frequency. Eight spin locking times (1, 2, 3, 5, 10, 15,20 , and $30 \mathrm{~ms}$ ) were used, with 500 acquisitions per $\mathrm{T}_{1}$ point. Data acquisition for the ${ }^{13} \mathrm{C}$ spectra was a 4-s recycle delay, a 2-ms cross-polarization contact time, 2048 acquisition points (51.2 ms acquisition time), and 1000 acquisitions.

Data processing was done the same way for all spectra and was done in the TNMR software package (Tecmag, Houston, TX). The first 512 points (13.3 ms acquisition time) were used and Fourier transformed with $20 \mathrm{~Hz}$ of line broadening. The spectra (supplemental 1) were individually phased and integrated using abovementioned limits and the fit to the equations above. The central one third of the peaks was used for the integration to obtain the best data and minimize error of the peak integrations. The error presented for the peaks is the error of the fit from the KaleidaGraph fitting. Protein and sugar relaxation times were considered different if they were more than two fitting errors apart.

\section{Storage Stability}

To evaluate the stabilizing effects of the different sugars, the different formulations were subjected to an accelerated storage stability test. Samples were stored at $60^{\circ} \mathrm{C}$ up to 90 days. Samples were taken from the freezer at different time points, so they could all be analyzed together, 
eliminating assay variations. The storage temperature was below the glass transition temperature $(\mathrm{Tg})$ of all samples tested, and they therefore remained physically as original during storage.

\section{High Pressure Size Exclusion Chromatography (HPSEC)}

HPSEC was conducted to provide information on aggregation of the IgG. The samples which were reconstituted with $1 \mathrm{~mL}$ ultrapure water were diluted further to a concentration of $1 \mathrm{mg} / \mathrm{mL} \mathrm{IgG}$ with $20 \mathrm{mM} \mathrm{NaH} \mathrm{PO}_{4}$ with $150 \mathrm{mM} \mathrm{NaCl}$ (pH 7.5). The samples were filtered using a $0.45-\mu \mathrm{m}$ filter before being injected on a Superose 6 GL 10/ 30 column in $100-\mu \mathrm{L}$ aliquots. The mobile phase was the same as the dilution buffer, and the flow used was $0.5 \mathrm{~mL} / \mathrm{min}$. Detection was done spectrophotometrically at $214 \mathrm{~nm}$.

Baseline corrections based on the signals between 6 and 7 and 26-27 min were carried out for the obtained chromatograms. The area under the curve of the monomer peak ( $\sim 16 \mathrm{~min})$ was determined from half height to half height of the peak. Degradation kinetics were established by correlating monomer peak area and the square root of storage time and carrying out a linear regression analysis; the slope of that curve was used as a measure for the aggregation rate. To limit aggregation after reconstitution of the samples, each sample was measured only once.

\section{Enzyme-Linked Immunosorbent Assay (ELISA)}

Since HPSEC only provides information about the aggregation of $\operatorname{IgG}$ but does not give information about functionality, an ELISA was conducted on the same samples to provide additional information. The integrity of the epitope of $\operatorname{IgG}$ was used as a measure for its stability. This was established using a bovine IgG ELISA kit supplied by Bethyl (Montgomery, TX, USA). Lyophilized samples were reconstituted using $1 \mathrm{~mL}$ of ultrapure water and diluted to concentrations between 500 and $7.8 \mathrm{ng} / \mathrm{mL}$ using diluent buffer, which consisted of $50 \mathrm{mM}$ Tris with $0.14 \mathrm{M} \mathrm{NaCl}$ and $0.05 \%$ Tween 20 ( $\mathrm{pH} 8.0$ ). Analysis was carried out on 96well plates, which were pre-incubated with affinity-purified bovine IgG coating antibody for an hour at room temperature and subsequently blocked with blocking solution, using the diluent buffer, at the same temperature for $30 \mathrm{~min}$. The diluted samples were incubated for an hour at room temperature, followed by incubation of horseradish peroxidase-conjugated bovine $\mathrm{IgG}$ detection antibody for an hour. Lastly, a substrate solution containing 3,3',5,5'tetramethybenzidine (TMB) was added and incubated in the dark during $15 \mathrm{~min}$ at room temperature. The reaction was stopped by addition of $0.18 \mathrm{M} \mathrm{H}_{2} \mathrm{SO}_{4}$, after which the conversion of TMB by peroxidase was measured spectrophotometrically at $450 \mathrm{~nm}$. The plates were washed five times with diluent buffer between all steps up to the addition of TMB. The absorbance was related to an unprocessed reference sample, giving an indication of the amount of epitopes still intact. Results were not related to $t=0$ as some formulations already showed loss of epitopes during lyophilization. Each sample was measured in four dilutions, and results from the two optimal dilutions were averaged. A duplicate analysis of a large part of the formulations provided nearly identical results.

\section{RESULTS}

\section{Solid-State Nuclear Magnetic Resonance Spectroscopy}

For the formulations of trehalose, dextran $1.5 \mathrm{kDa}$, and both inulins, the ${ }^{1} \mathrm{H} \mathrm{T}_{1}$ relaxation times of protein and sugar are indistinguishable (Fig. 2a). For dextran 5 and $70 \mathrm{kDa}$, the values of the protein and sugar are clearly different, with a bigger difference in ${ }^{1} \mathrm{H} \mathrm{T}_{1}$ relaxation times for the formulation of dextran $70 \mathrm{kDa}$. This is indicative of phase separation at the $20-50-\mathrm{nm}$ scale for formulations with dextran 5 and $70 \mathrm{kDa}$ and IgG. For the formulations with $\mathrm{IgG}$ and trehalose, both inulins, and dextran $1.5 \mathrm{kDa}$, there is no indication of phase separation on this scale.

In addition to phase separation, there is a trend in the ${ }^{1} \mathrm{H}$ $\mathrm{T}_{1}$ relaxation time, where the lower molecular weight sugar systems had the longest relaxation time, and the protein relaxation time decreases as the sugar molecular weight increases. Since ${ }^{1} \mathrm{H}_{1}$ relaxation times are indicators of molecular mobility, the longer relaxation times would correlate with a lower molecular mobility $(20,21)$. The absolute ${ }^{1} \mathrm{H} \mathrm{T}_{1}$ relaxation time of $\mathrm{IgG}$ is highest for the smallest sugar trehalose and decreases when the molecular weight of the combined sugar increases, suggesting less molecular mobility of the protein when incorporated in the low molecular weight sugar.

The ${ }^{1} \mathrm{H} \mathrm{T}_{1 \rho}$ relaxation times of $\mathrm{IgG}$ do not show an increase with lower molecular weight (Fig. 2b). ${ }^{1} \mathrm{H} \mathrm{T}_{1 \rho}$ relaxation times are indistinguishable for trehalose and $\mathrm{IgG}$, somewhat different for the inulin formulations, and even more different for the formulations containing dextran. This indicates miscibility down to the 2-5-nm scale for trehalose. The other formulations show immiscibility on this scale. Therefore, combinations of $\operatorname{IgG}$ with both inulins and dextran $1.5 \mathrm{kDa}$ are classified as partially phase separated, whereas dextrans 5 and $70 \mathrm{kDa}$ are phase separated and trehalose and $\mathrm{IgG}$ are fully miscible.

\section{Storage Stability-HPSEC}

During storage at $60^{\circ} \mathrm{C}$, the formulation containing trehalose shows nearly no aggregation of $\mathrm{IgG}$ (Fig. 3). For the other sugars, there is an increasing degree of $\mathrm{IgG}$ aggregation with increasing molecular weight of the sugar, with the exception of dextran $5 \mathrm{kDa}$. The formulation with dextran $1.5 \mathrm{kDa}$ shows $\sim 20 \%$ of aggregation of $\mathrm{IgG}$ after 90 days of storage, and for inulin $1.8 \mathrm{kDa}$ and dextran $5 \mathrm{kDa}$, this is $\sim 40 \%$. Inulin $4 \mathrm{kDa}$ shows $\sim 50 \%$ loss of monomer, and lastly there was no clear difference in aggregation between the formulation without sugar and that with dextran $70 \mathrm{kDa}$. The aggregation results correlate with the ${ }^{1} \mathrm{H}_{1}$ relaxation times of the protein and are consistent with the more stable samples being fully or partially miscible and the phase separated samples having the poorest stability. 


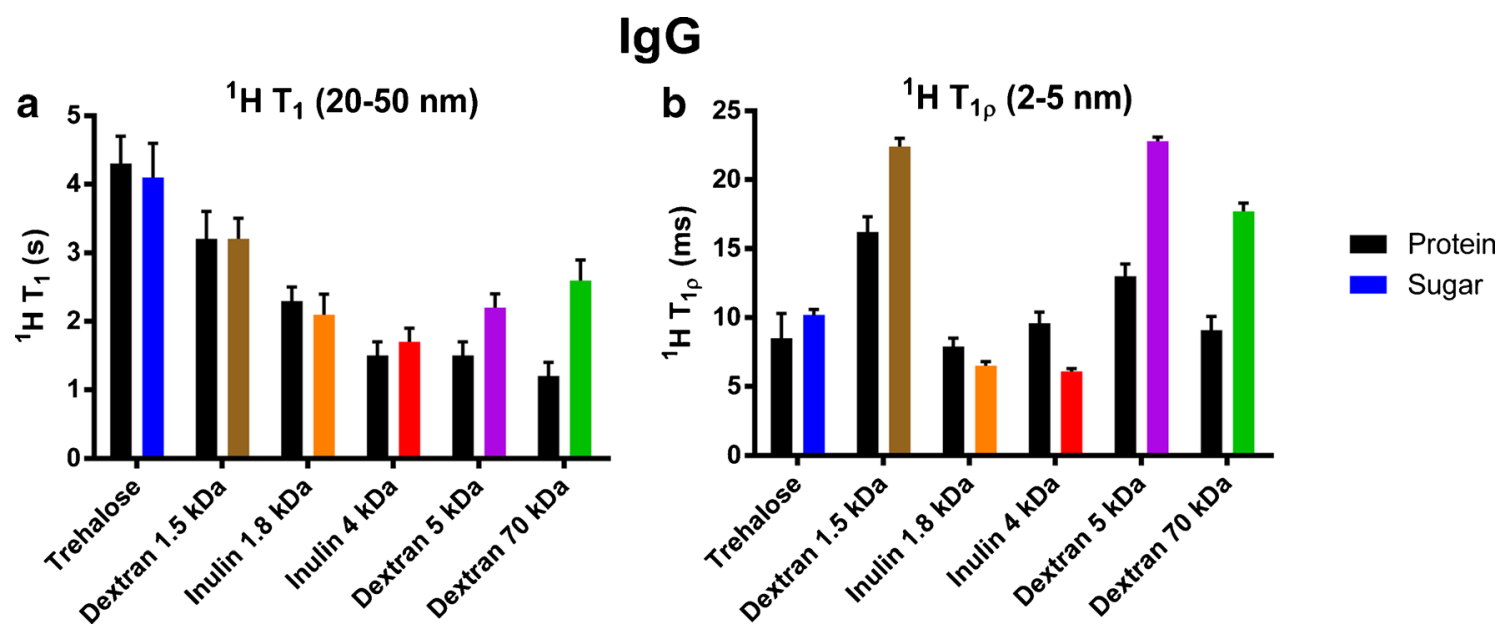

Fig. 2. Spin-lattice relaxation times $\left({ }^{1} \mathrm{H} \mathrm{T}_{1}\right.$, left $)$ and rotating frame spin-lattice relaxation times $\left({ }^{1} \mathrm{H} \mathrm{T}_{1 \rho}\right.$, right $)$ of both protein and sugar from lyophilizates of $\mathrm{IgG}$ with various sugars. The formulations are ordered by molecular weight of the sugar, increasing from left to right

\section{Storage Stability-ELISA}

As with aggregation, the formulation of $\mathrm{IgG}$ and trehalose shows little or no change in amount of intact epitopes during storage (Fig. 4). Inulin $4 \mathrm{kDa}$ shows a loss of around $30 \%$ of epitopes, and the formulations with dextran $70 \mathrm{kDa}$ and the formulation without sugar lost $\sim 40 \%$ of epitopes. Remarkably, the smaller inulin $1.8 \mathrm{kDa}$ and the two smaller dextrans 1.5 and $5 \mathrm{kDa}$ show a bigger loss of intact epitopes than the formulation without sugar, a total loss of $\sim 50 \%, \sim 70 \%$, and $\sim 60 \%$, respectively. This indicates a deteriorative effect of the sugar on the protein, which could indicate that the reducing groups of the sugar reacted with the amine groups of the protein, the so-called Maillard reaction. Initial Maillard browning could affect the functional epitopes of IgG and therewith the ELISA data, but because of the molecular weight of these sugars compared to that of $\mathrm{IgG}$, it would likely not impact HPSEC results significantly. Some discoloration was observed in the samples with dextran $1.5 \mathrm{kDa}$, dextran $5 \mathrm{kDa}$, and inulin $1.5 \mathrm{kDa}$ after 90 days. Most discoloration was found in the formulation containing dextran $1.5 \mathrm{kDa}$. There was no observable discoloration for formulations with trehalose, inulin $4 \mathrm{kDa}$ and dextran
$70 \mathrm{kDa}$. It should be noted, however, that other chemical degradation reactions could not be ruled out.

\section{DISCUSSION}

In this study, the influence of miscibility of protein-sugar lyophilizates on the storage stability was investigated using model protein $\mathrm{IgG}$. Miscibility was evaluated by comparing SsNMR relaxation times at two timescales, providing information on miscibility on 2-5- and 20-50-nm length scales. When ${ }^{1} \mathrm{H} \mathrm{T}_{1}$ relaxation times of protein and sugar were different for a single sample, this indicated immiscibility of the system already on the larger $20-50-\mathrm{nm}$ scale and these combinations were classified as immiscible. When ${ }^{1} \mathrm{H} \mathrm{T}_{1}$ relaxation times were similar, but ${ }^{1} \mathrm{H} \mathrm{T}_{1 \rho}$ relaxation times, with a diffusion length scale of 2-5 nm, were different, the combination was considered partially phase separated. If both ${ }^{1} \mathrm{H} \mathrm{T}_{1}$ and ${ }^{1} \mathrm{H} \mathrm{T}_{1 \rho}$ relaxation times were similar, there was no indication of phase separation and the sample was deemed miscible. Table I shows the classifications of all the tested combinations, based on this rationale.

Previously, we reported that smaller and molecularly more flexible sugars were better capable of stabilizing

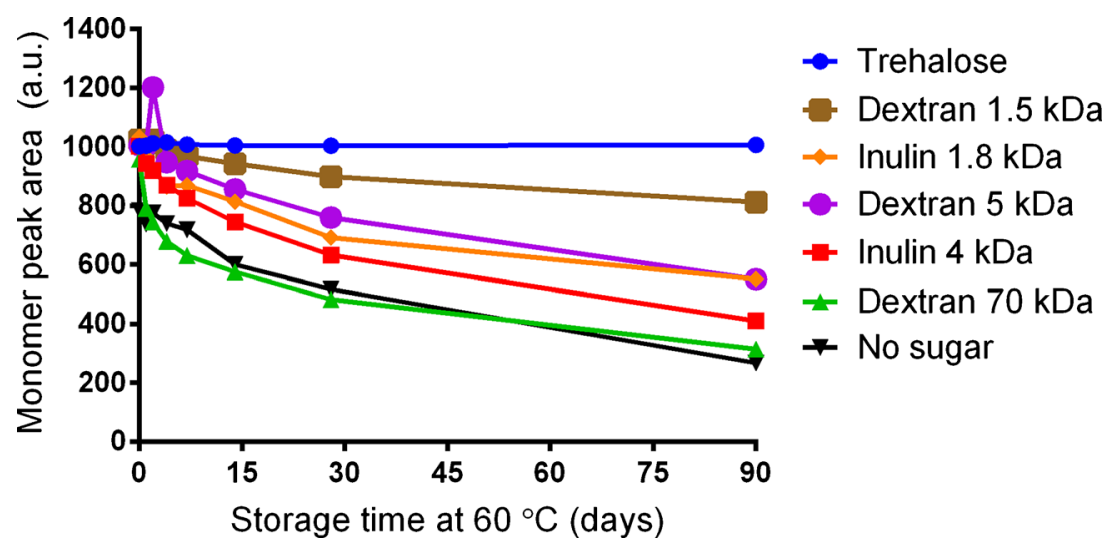

Fig. 3. Amount of unaggregated $\operatorname{IgG}$ (soluble monomer) of $\operatorname{IgG}$ lyophilized with various sugars during storage at $60^{\circ} \mathrm{C}$ during 90 days 


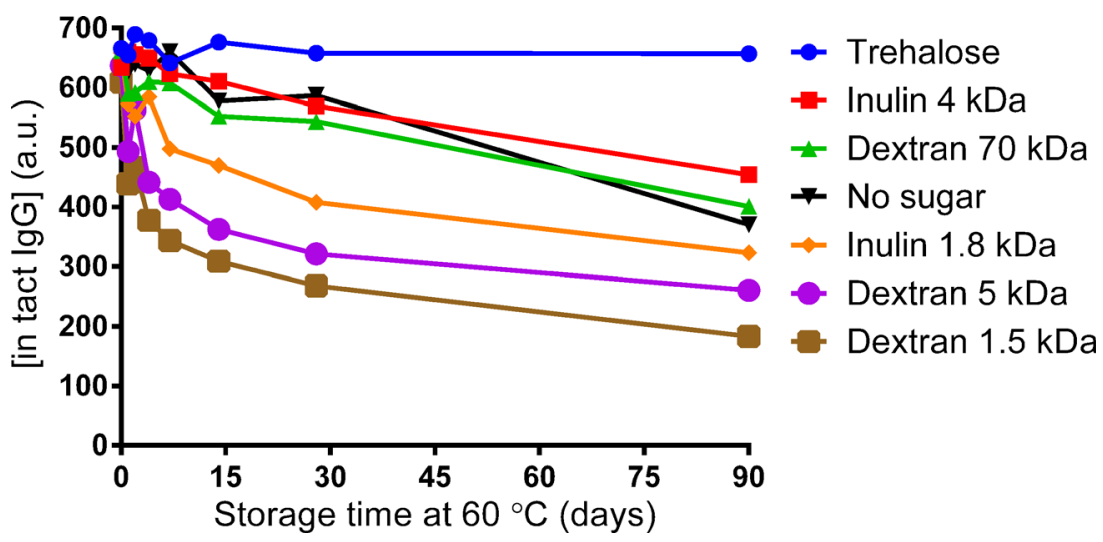

Fig. 4. Amount of intact epitopes of $\mathrm{IgG}$ lyophilized with various sugars during storage at $60^{\circ} \mathrm{C}$ during 90 days

proteins during lyophilization (11), as they were less inhibited by steric hindrance and configurational inflexibility and therewith better able to form hydrogen bonds with the protein during lyophilization (12). Here, it was found that miscibility and absolute ${ }^{1} \mathrm{H} \mathrm{T}_{1}$ relaxation times decreased with increasing molecular weight of the sugar used. ${ }^{1} \mathrm{H} \mathrm{T}_{1}$ relaxation times have been shown to be predictive for physical stability of amorphous systems (22) and protein storage stability (20), presumably because the molecular mobility involved in generating the ${ }^{1} \mathrm{H} \mathrm{T}_{1}$ relaxation process is similar to the molecular mobility that causes degradation. Here too, protein ${ }^{1} \mathrm{H}_{1} \mathrm{~T}_{1}$ relaxation times correlate with protein aggregation rates (Fig. 5).

The overall size of IgG is significantly larger than 2$5 \mathrm{~nm}$, with a total maximum length of $\sim 16 \mathrm{~nm}$ (23). However, the protein is not a sphere and its subdomains (chains) are smaller, with dimensions of approximately $2.5 \times 2.5 \times 5 \mathrm{~nm}$ (24). Therefore, these miscibility data likely describe the ability of sugars to enter empty spaces in the protein's threedimensional structure and form intimate contact. Thus, the miscibility we describe here could possibly indirectly indicate steric hindrance of the protein and sugar. This is in line with our previous findings, as a close proximity of the sugar to the protein is prerequisite for hydrogen bonding and therewith stabilization. It is therefore not surprising that the smallest sugar tested, disaccharide trehalose, is the best stabilizer of IgG as represented by both the HPSEC and ELISA storage stability data and that stabilizing capacity diminishes with increasing molecular weight of the stabilizer.
The ELISA data do not correlate as well with the miscibility data as the HPSEC results do. Most likely, this is because of an additional mechanism of degradation, presumably the Maillard reaction or other chemical degradation reactions. Inulin without the glucose end group and dextran both have a reducing end group, which is relatively more abundant in lower molecular weight sugars (25). This would explain why the smaller dextrans $(1.5$ and $5 \mathrm{kDa})$ and smaller inulin $(1.8 \mathrm{kDa})$ maintain less functional epitopes than the protein without sugar. As mentioned previously, chemical bonding of a sugar of $1.5-5 \mathrm{kDa}$, as happens in the initial steps of the Maillard cascade, does not have a large impact on the total mass and three-dimensional size of $\mathrm{IgG}$, which has a molecular weight of approximately $150 \mathrm{kDa}$. Therefore, HPSEC is insensitive to Maillard reactions with relatively small oligosaccharides, unlike the ELISA assay which will detect these changes if they impact the functional epitope directly or indirectly do so by causing conformational changes.

In this study, a sugar-to-protein weight ratio of approximately 7:1 was used, which is on the low end of ratio's commonly used in protein-sugar lyophilizates (26). The sugarto-protein ratio most likely influences miscibility. As the relative amount of sugar increases, saturation of the microenvironment of the protein can occur, resulting in phase separation. This was not observed here, as the formulation with trehalose was found to be miscible. However, using this concept, it should be possible to establish at which sugarprotein ratio saturation occurs by measuring different sugar-

Table I. Classification of Miscibility Based on ssNMR Relaxation Times of Protein-Sugar Lyophilizates

\begin{tabular}{|l|c|ccl|}
\hline & MW (kDa) & $20-50 \mathrm{~nm}$ & $2-5 \mathrm{~nm}$ & Classification \\
\hline Trehalose & 0.3 & $\bullet$ & $\bullet$ & Miscible \\
Dextran & 1.5 & $\bullet$ & $\bullet$ & Partially phase separated \\
Inulin & 1.8 & $\bullet$ & $\bullet$ & Partially phase separated \\
Inulin & 4 & $\bullet$ & $\bullet$ & Partially phase separated \\
Dextran & 5 & $\bullet$ & $\bullet$ & Phase separated \\
Dextran & 70 & $\bullet$ & $\bullet$ & Phase separated \\
\hline
\end{tabular}

$M W$ molecular weight, $\bullet$ similar relaxation times, $\bullet$ different relaxation times 


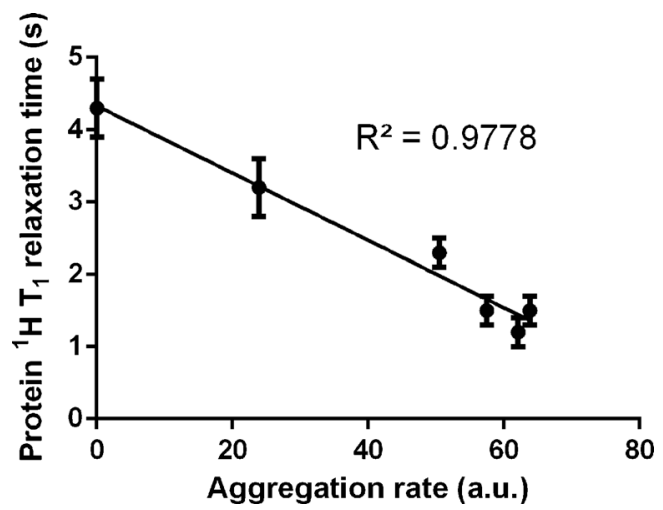

Fig. 5. Correlation between protein aggregation rate (loss of monomer per the square root of time during storage as determined with HPSEC) versus protein ${ }^{1} \mathrm{H} \mathrm{T}_{1}$ relaxation times for the different formulations

protein ratios of one formulation. Knowing at which point saturation occurs could be useful information for formulation development.

Considering the above, smaller non-reducing sugars are preferred for stabilizing proteins as they are less limited by steric hindrance and are thus more miscible with the protein. However, these sugars are generally characterized by a lower $\mathrm{Tg}$, and with that, care should be taken that vitrification of the formulation is maintained during storage (27). That is, one should not exceed the glass transition temperature. This is particularly a problem in case of higher levels of residual moisture or moisture sorption, as water has a strong plasticizing effect on sugar glasses (28). In cases where the $\mathrm{Tg}$ would not be adequate for the planned storage conditions (i.e., approximately $10-20^{\circ} \mathrm{C}$ higher than the storage temperature (29)), combining a large polysaccharide with a nonreducing disaccharide is a suitable alternative $(30,31)$. This limits steric hindrance as much as possible, while achieving a high enough $\mathrm{Tg}$ (11).

\section{CONCLUSION}

In summary, ssNMR is able to detect miscibility on a level close to the size of the protein molecules and the obtained miscibility classifications and ${ }^{1} \mathrm{~T} \mathrm{H}_{1}$ relaxation times correlate well with aggregation rates of $\mathrm{IgG}$ during storage. The ELISA storage stability data show degradation by both aggregation and Maillard browning or other chemical degradation reactions, which cannot be deconvoluted accurately. Smaller sugars show better protein-sugar miscibility as they are less influenced by steric hindrance, and this makes them more suitable as stabilizers of proteins.

\section{ACKNOWLEDGMENTS}

This research was jointly financed by Royal FrieslandCampina, the European Union, European Regional Development Fund and The Ministry of Economic Affairs, Agriculture and Innovation, Peaks in the Delta, the Municipality of Groningen, the Provinces of Groningen, Fryslân, and Drenthe as well as the Dutch Carbohydrate Competence Center.
We acknowledge Ms. de Ruiter and Mr. Scheffer of Royal FrieslandCampina for their analytical support.

MJN and EJM acknowledge support from the NSF I/ UCRC Center for Pharmaceutical Development (IIP-1063879 and industrial contributions) for financial support. The solidstate NMR results presented here are from academic work performed at the University of Kentucky, and no data from Kansas Analytical Services are presented. EJM is a partial owner of Kansas Analytical Services, a company that provides solid-state NMR services to the pharmaceutical industry.

Open Access This article is distributed under the terms of the Creative Commons Attribution 4.0 International License (http://creativecommons.org/licenses/by/4.0/), which permits unrestricted use, distribution, and reproduction in any medium, provided you give appropriate credit to the original author(s) and the source, provide a link to the Creative Commons license, and indicate if changes were made.

\section{REFERENCES}

1. U.S. Food and Drug Administration Center for Drug Evaluation and Research. Novel new drugs 2014 summary [Internet]. FDA. 2015. Available from: http://www.fda.gov/ downloads/Drugs/Development ApprovalProcess/ DrugInnovation/UCM430299.pdf

2. Carpenter JF, Pikal MJ, Chang BS, Randolph TW. Rational design of stable lyophilized protein formulations: some practical advice. Pharm Res. 1997;14(8):969-75.

3. Wang W. Lyophilization and development of solid protein pharmaceuticals. Int J Pharm. 2000;203(1-2):1-60.

4. Chang L, Shepherd D, Sun J, Ouellette D, Grant KL, Tang X, et al. Mechanism of protein stabilization by sugars during freezedrying and storage: native structure preservation, specific interaction, and/or immobilization in a glassy matrix? J Pharm Sci. 2005;94(7):1427-44.

5. Chang L, Pikal M. Mechanisms of protein stabilization in the solid state. J Pharm Sci. 2009;98(9):2886-908.

6. Manning MC, Chou DK, Murphy BM, Payne RW, Katayama DS. Stability of protein pharmaceuticals: an update. Pharm Res. 2010;27(4):544-75.

7. Yoshioka S, Aso Y. Correlations between molecular mobility and chemical stability during storage of amorphous pharmaceuticals. J Pharm Sci. 2007;96(5):960-81.

8. Yuan X, Sperger D, Munson EJ. Investigating miscibility and molecular mobility of nifedipine-PVP amorphous solid dispersions using solid-state NMR spectroscopy. Mol Pharm. 2014;11(1):329-37.

9. Bovey FA, Mirau PA. NMR of polymers. 1st ed. San Diego: Academic; 1996.

10. Aso Y, Yoshioka S, Miyazaki T, Kawanishi T, Tanaka K, Kitamura S, et al. Miscibility of nifedipine and hydrophilic polymers as measured by (1)H-NMR spin-lattice relaxation. Chem Pharm Bull (Tokyo). 2007;55(8):1227-31.

11. Tonnis WF, Mensink MA, de Jager A, van der Voort Maarschalk K, Frijlink HW, Hinrichs WLJ. Size and molecular flexibility of sugars determine the storage stability of freeze-dried proteins. Mol Pharm. 2015;12(3):684-94.

12. Mensink MA, Van Bockstal P-J, Pieters S, De Meyer L, Frijlink HW, van der Voort Maarschalk K, et al. In-line near infrared spectroscopy during freeze-drying as a tool to measure efficiency of hydrogen bond formation between protein and sugar, predictive of protein storage stability. Int J Pharm. 2015;496(2):792-800.

13. Sigma-Aldrich. Product information $\mathrm{IgG}$ from bovine serum [Internet]. 2015 [cited 2015 Dec 27]. Available from: http:// 
www.sigmaaldrich.com/content/dam/sigma-aldrich/docs/Sigma/ Product_Information_Sheet/2/i9640pis.pdf

14. Patel SM, Doen T, Pikal MJ. Determination of end point of primary drying in freeze-drying process control. AAPS PharmSciTech. 2010;11(1):73-84.

15. Andrew ER, Bradbury A, Eades RG. Removal of dipolar broadening of nuclear magnetic resonance spectra of solids by specimen rotation. Nature. 1959;183(4678):1802-3.

16. Pines A, Gibby M, Waugh J. Proton-enhanced NMR of dilute spins in solids. J Chem Phys. 1973;59(2):569.

17. Dixon W, Schaefer J, Sefcik M, Stejskal E, McKay R. Total suppression of sidebands in CPMAS C-13 NMR. J Magn Reson. 1982;49(2):341-5.

18. Fung BM, Khitrin AK, Ermolaev K. An improved broadband decoupling sequence for liquid crystals and solids. J Magn Reson. 2000;142(1):97-101.

19. Barich DH, Gorman EM, Zell MT, Munson EJ. 3-Methylglutaric acid as a 13C solid-state NMR standard. Solid State Nucl Magn Reson. 2006;30(3-4):125-9.

20. Lam Y-H, Bustami R, Phan T, Chan H-K, Separovic F. A solidstate NMR study of protein mobility in lyophilized protein-sugar powders. J Pharm Sci. 2002;91(4):943-51.

21. Yoshioka S, Aso Y, Kojima S. Different molecular motions in lyophilized protein formulations as determined by laboratory and rotating frame spin-lattice relaxation times. J Pharm Sci. 2002;91(10):2203-10.

22. Dempah KE, Barich DH, Kaushal AM, Zong Z, Desai SD, Suryanarayanan $\mathrm{R}$, et al. Investigating gabapentin polymorphism using solid-state NMR spectroscopy. AAPS PharmSciTech. 2013;14(1):19-28.
23. Harris LJ, Larson SB, Hasel KW, McPherson A. Refined structure of an intact IgG2a monoclonal antibody. Biochemistry. 1997;36(7):1581-97.

24. Reth M. Matching cellular dimensions with molecular sizes. Nat Immunol. 2013;14(8):765-7.

25. Mensink MA, Frijlink HW, van der Voort Maarschalk K, Hinrichs WLJ. Inulin, a flexible oligosaccharide I: review of its physicochemical characteristics. Carbohydr Polym. 2015;130:405-19.

26. Mensink MA, Frijlink HW, Vander Voort Maarschalk K, Hinrichs WLJ. Inulin, a flexible oligosaccharide II: review of its pharmaceutical applications. Carbohydr Polym. 2015;134:418-28. Elsevier Ltd.

27. Crowe JH, Carpenter JF, Crowe LM. The role of vitrification in anhydrobiosis. Annu Rev Physiol. 1998;60(1):73-103.

28. Roos Y, Karel M. Plasticizing effect of water on thermal behavior and crystallization of amorphous food models. J Food Sci. 1991;56(1):38-43.

29. Grasmeijer N, Stankovic M, de Waard H, Frijlink HW, Hinrichs WLJ. Unraveling protein stabilization mechanisms: vitrification and water replacement in a glass transition temperature controlled system. Biochim Biophys Acta Proteins Proteomics. 2013;1834(4):763-9.

30. Allison SD, Manning MC, Randolph TW, Middleton K, Davis A, Carpenter JF. Optimization of storage stability of lyophilized actin using combinations of disaccharides and dextran. J Pharm Sci. 2000;89(2):199-214.

31. Garzon-Rodriguez W, Koval RL, Chongprasert S, Krishnan S, Randolph TW, Warne NW, et al. Optimizing storage stability of lyophilized recombinant human interleukin-11 with disaccharide/ hydroxyethyl starch mixtures. J Pharm Sci. 2004;93(3):684-96. 